CDD: 379

\title{
MARCOS LEGAIS PARA OS CURSOS DE GRADUAÇÃO EM PEDAgOgIA NO BRASIL: ANÁLISE dAS ATRIBUIÇõéS dO PEDAgOgo
}

\author{
LEGAL FRAMEWORKS FOR EDUCATION'S GRADUATE PROGRAMS IN BRASIL: \\ ANALYSIS OF THE ATTRIBUTIONS OF THE EDUCATOR \\ MARCOS LEGALES PARA LAS CARRERAS DE GRADUACIÓN EN PEDAGOGÍA EN EL \\ BRASIL: ANÁLISIS DE LAS ATRIBUCIONES DEL PEDAGOGO

\section{Rosana Sousa Pereira Lopes ${ }^{1}$ Luciane Guimarães Batistella Bianchini ${ }^{2}$ Nelson Pedro Silva ${ }^{3}$}

RESUMO: As Diretrizes Curriculares Nacionais atuais estabelecem como parâmetros para os cursos de Pedagogia a formação de docentes e de profissionais para a realização de atividades de apoio escolar (gestão) e pesquisas educacionais. Nosso objetivo foi o de analisar as atribuições do pedagogo desde 1930. Para tal, realizamos uma análise documental das principais leis que nortearam as atividades realizadas por esse profissional. Buscamos demonstrar como o pedagogo se transformou de "velho" mestre-escola (1854-1880) em professor de instrução primária (final dos séculos XIX e XX) e, hodiernamente, em um "faz tudo" nas escolas e nas instâncias de administração dessas instituições. Esperamos, com tais análises, contribuir para a definição das atribuições do pedagogo na atualidade e oferecer conhecimentos para reflexão aos alunos dos cursos de graduação em Pedagogia no Brasil, auxiliando na formação desses futuros profissionais.

PAlaVRAS-ChAVE: Políticas públicas em educação. Docência. Gestão da escola. Função.

ABSTRACT: The current National Curricular Guidelines sets as parameters for Education's programs the teaching and professional training in order to allow the realization of activities of school tutoring (management) and educational research. Our objective was to analyze educators' attributions since 1930. For that, we made an analysis of the main laws that guided the activities of these professionals. We tried to demonstrate how the educator became from an "old" school teacher (1854-1880) to a primary education professor (end of XIX and XX centuries) and, nowadays, in a "make it all" in schools and in the administrative tasks into the schools. We hope, with this analysis, to contribute to the definition of attributions of the educator in current days and to offer subsidies for a better thinking of the process to students of Education in Brasil, helping in the tutoring of those future professionals.

KEYWORDS: Public policies in education.Teaching. School management. Function.

RESUMEN: Las Directrices Curriculares Nacionales actuales establecen como parámetros para las carreras de Pedagogía la formación de docentes y profesionales para la realización de actividades de apoyo escolar (gestión)

\footnotetext{
${ }^{1}$ Pedagoga formada pela UEL. Mestrado em Educação pela Unimep - Piracicaba-SP, Doutorado em Educação e Currículo - PUC-SP. Universidade Estadual de Londrina. Professora Doutora do Departamento de Educação da Área de Políticas e Gestão. Londrina- Paraná - Brasil. E-mail: rosanalopes@uel.br

${ }^{2}$ Psicopedagoga e Pedagoga formada pela UEL. Mestrado em Educação pela UEL. Doutorado em Psicologia do Desenvolvimento Humano - Unesp - Assis-SP. Pós-doutoranda em Psicologia do Desenvolvimento Humano Unesp - Assis-SP.Professora Doutora convidada no curso de Psicopedagogia UEL - Londrina-PR - Brasil. Email: luannbi@hotmail.com

${ }^{3}$ Psicólogo formado pela Unesp. Mestrado em Psicologia da Educação pela PUC-SP. Doutorado em Psicologia Escolar e do Desenvolvimento Humano pela USP-SP. Especialista em Psicopedagogia e em Psicologia Ética e Moral. Professor Doutor do Departamento de Psicologia Evolutiva, Social e Escolar do Curso de Psicologia da Unesp - Assis-São Paulo - Brasil. E-mail: nelsonp1 @ terra.com.br
}

Recebido em:13/11/2014 - Aceito em: 16/12/2014

\begin{tabular}{l|l|l|l|l|l|l} 
(C) ETD-Educ. temat. digit. & Campinas, SP & v.16 & n.3 & p.458-474 & set./dez. 2014 & ISSN 1676-2592
\end{tabular}


y pesquisas educacionales. Nuestro objetivo fue el de analizar las atribuciones del pedagogo desde 1930. Para eso, realizamos un análisis documental de las principales leyes que nortearon las actividades realizadas por este profesional. Intentamos demostrar cómo el pedagogo se transformó de "viejo" maestro de escuela (1854-1880) en profesor de instrucción primaria (final de los siglos XIX e XX) y, en los días actuales, en un "todo terreno" en las escuelas y en las instancias de administración de esas instituciones. Esperamos, con los mencionados análisis, contribuir para la definición de las atribuciones del pedagogo en la actualidad y ofrecer conocimientos para la reflexión a los alumnos de las carreras de graduación en Pedagogía en el Brasil, auxiliando en la formación de esos futuros profesionales.

PAlabras ClavE: Políticas públicas en educación. Docencia. Gestión de escuela. Función.

\section{INTRODUÇÃO}

A compreensão das atribuições do pedagogo na atualidade nos obriga a olhar para as determinações legais previstas para sua formação. É com base nessas legislações que se instituem as tarefas a serem realizadas por esse profissional.

Conforme as Diretrizes Curriculares para o Curso de Graduação em Pedagogia de 2006 - DCNP - CNE/CP n ${ }^{0}$ 1/06 (BRASIL, 2006a), os cursos de formação de pedagogos devem organizar seu currículo obedecendo a três eixos: a docência (eixo central), a gestão e a produção de conhecimento.

A ênfase na docência justifica-se, ainda de acordo com as referidas diretrizes, por ser considerada a base da formação do pedagogo. Sheibe e Durli (2011), em consonância com os grupos que defenderam essa orientação legal, entre eles a Associação Nacional pela Formação de Profissionais de Educação (Anfope) e o Fórum Nacional de Diretores de Faculdade, Centros de Educação e Equivalentes (Forumdir), entenderam que essa ênfase supera a fragmentação observada na formação dos pedagogos, conforme o Parecer 252/69 (BRASIL, 1969).

No entanto, Pimenta (2006) e Libâneo (2006) teceram críticas ao fato de a docência configurar-se como a base da formação desse profissional, expresso no Manifesto dos Educadores organizado em 2005.

Para Libâneo (2006), os cursos de Pedagogia devem priorizar a produção de conhecimentos pedagógicos. Afinal, o fenômeno educativo deve ser compreendido pelos pedagogos em sua complexidade, ou seja, não de modo isolado e estático, mas como um processo articulado a vários fatores, entre eles, o aluno em seu processo de socialização e aprendizagem e os agentes de formação (educadores, pais, comunidade e o contexto socioinstitucional com suas normas e procedimentos).

Pimenta (2006) ressalta ainda que a docência como base da formação do pedagogo acabou por fragilizar sua atuação profissional no âmbito escolar e até nos próprios cursos de Pedagogia. Para a referida pesquisadora, ao enfatizar a docência, acabou-se por retirar dos 
cursos de formação o campo pedagógico como área de atuação e produção de conhecimento. Assim como Libâneo (2006), Pimenta (2006) defende que o eixo da formação do pedagogo deve ser a pesquisa na área de educação.

Esses autores também criticam a definição das atividades docentes apresentada no parágrafo único do Artigo $4^{\circ}$ das referidas Diretrizes (BRASIL, 2006a), que eles julgam demasiadamente ampla:

\footnotetext{
As atividades docentes também compreendem participação na organização e gestão de sistemas e instituições de ensino, englobando:

I - planejamento, execução, coordenação, acompanhamento e avaliação de tarefas próprias do setor da Educação;

II - planejamento, execução, coordenação, acompanhamento e avaliação de projetos e experiências educativas não escolares;

III - produção e difusão do conhecimento científico-tecnológico do campo educacional, em contextos escolares e não escolares. (BRASIL, 2006b, p. 20)
}

Esse entendimento evidencia que os cursos de Pedagogia devem ter por objetivo principal a formação de docentes para o desempenho da ação educativa, seja ela na Educação Infantil, nos anos iniciais do Ensino Fundamental, na formação profissional oferecida no Ensino Médio ou na Gestão Escolar, tanto em espaços educativos formais quanto informais.

A esse respeito, autores que fazem parte da Anfope - como Scheibe e Durli (2011) e Brezeinski (1996) - defendem a ênfase na docência desde que ela seja compreendida em sentido ampliado, isto é, o exercício do magistério, a gestão escolar e a produção de conhecimentos na área educacional. Conforme esses especialistas, todas as atribuições do pedagogo requerem conhecimentos da docência; portanto, as citadas Diretrizes (BRASIL, 2006a) aderiram ao sentido de docência da Anfope.

Vê-se, então, que o pedagogo deve ter uma formação flexível e adaptável. Todavia, como aponta Campos (2004), ela se inclina para a produção de um profissional polivalente. Por isso, aumentam suas funções e responsabilidades, além daquelas relacionadas ao processo de ensino-aprendizagem.

Küenzer e Rodrigues (2006), a esse respeito, afirma que tal perspectiva representa uma totalidade vazia. É quase impossível o oferecimento de uma formação profissional para o exercício de tantas competências (docência, gestão e pesquisa).

Observamos que, na tentativa de atender às demandas das Diretrizes (BRASIL, 2006a), atualmente, além de confuso, o papel do pedagogo é tão amplo que não é possível saber quais são suas atribuições. Por causa disso, muitas vezes, esse profissional se identifica e é identificado socialmente como professor da Educação Infantil e dos anos iniciais do Ensino Fundamental, ficando relegada ao plano secundário sua função de gestor e de pesquisador. 
Inferimos a existência de uma polêmica quanto à formação do pedagogo. De um lado, para a Anfope, a formação do pedagogo deve ter uma base comum, tendo como eixo principal a docência ampliada. Em outras palavras, é um trabalho pedagógico que evolve o exercício do magistério, as atividades da gestão e a produção de conhecimento. Por outro, conforme o Manifesto, a formação do pedagogo deve centra-se na produção do conhecimento sobre o fenômeno educativo, pois "toda a docência é trabalho pedagógico, mas nem todo trabalho pedagógico é docência”. (LIBANEO, 2006, p. 37).

Diante disso, começamos a nos questionar sobre as atribuições do pedagogo desde o início do século XX, tendo como parâmetro as várias legislações elaboradas desde aquela época até os dias atuais.

\section{OBJETIVOS}

Considerando tais aspectos, analisamos o papel do pedagogo brasileiro desde a década de 1930.

Sem desconsiderar as demais teses, buscamos defender que esse profissional se transformou substancialmente de "velho" mestre-escola (professor de instrução primária) no atual pedagogo (professor, pesquisador e gestor, ou seja, uma espécie de "faz-tudo").

\section{METODOLOGIA}

Nosso estudo é qualitativo e caracterizado como "pesquisa documental", realizada mediante a análise do Decreto $\mathrm{n}^{\circ}$ 1.190, de 1939 (BRASIL, 1939); da Lei $\mathrm{n}^{\circ}$ 5.540, de 1968 (BRASIL, 1968); do Parecer $n^{\circ}$ 252, de 1969 (BRASIL, 1969); da Lei ${ }^{\circ}$ 9.394, de 1996 (BRASIL, 1996) e das atuais Diretrizes Curriculares para o Curso de Pedagogia (BRASIL, 2006a).

As legislações analisadas são documentos de primeira mão, isto é, segundo Gil (2002), são aqueles que não receberam tratamento analítico, pois são de autoria de órgãos públicos, devendo ser conservados no modo como foram produzidos. A riqueza desse tipo de pesquisa está no fato de que é feita uma análise de um dado que se apresenta de modo estável, possibilitando ao pesquisador interpretações mais próximas de sua origem. Outro ponto positivo é o baixo custo desse tipo de pesquisa. Ela demanda do pesquisador apenas tempo disponível para analisar os documentos.

Cabe destacar que nosso objetivo nesta análise não foi considerar todos os itens presentes em tais legislações, mas sim aqueles referentes às atribuições delegadas ao pedagogo. Para isso, apresentamos a seguir os dados que destacamos em nosso trabalho (denominação; duração da formação; objetivo e atribuições decorrentes). 
QUADRO 1 - Decretos e leis sobre a atribuição do pedagogo.

\begin{tabular}{|c|c|c|c|}
\hline Legislação & Denominação & Objetivo & Atribuições decorrentes \\
\hline \multirow{2}{*}{$\begin{array}{c}\text { Decreto } \mathrm{n}^{\mathbf{o}} \\
1.190 / 39\end{array}$} & $\begin{array}{l}\text { Bacharel } \\
\text { "Técnico em } \\
\text { Educação" }\end{array}$ & $\begin{array}{l}\text { Formar especialista na } \\
\text { área de planejamento, } \\
\text { currículo e avaliação. }\end{array}$ & $\begin{array}{l}\text { Trabalhar em setores governamentais e nas } \\
\text { funções que envolvem a administração } \\
\text { escolar. }\end{array}$ \\
\hline & Licenciado & $\begin{array}{l}\text { Formar docente para o } \\
\text { curso de Magistério. }\end{array}$ & $\begin{array}{l}\text { Professor da formação de docentes para a } \\
\text { educação primária. }\end{array}$ \\
\hline $\begin{array}{l}\text { Lei } \mathrm{n}^{\mathrm{o}} \\
5.540 / 68 \mathrm{e} \\
\text { Parecer } \\
251 / 62\end{array}$ & $\begin{array}{l}\text { Bacharel e } \\
\text { Licenciado }\end{array}$ & $\begin{array}{l}\text { Formar docente para o } \\
\text { curso de Magistério e } \\
\text { especialista para atuar } \\
\text { no campo da } \\
\text { administração escolar e } \\
\text { em atividades } \\
\text { complementares a esta. }\end{array}$ & $\begin{array}{l}\text { Professor da formação pedagógica de } \\
\text { docentes para a educação primária e técnico- } \\
\text { pedagógico para atuarem nas funções que } \\
\text { envolvem a administração escolar. }\end{array}$ \\
\hline $\begin{array}{l}\text { Parecer } n^{\circ} \\
252 / 69 \\
\text { Fragmenta } \\
\text { específica }\end{array}$ & Licenciado & $\begin{array}{l}\text { Formar docente para o } \\
\text { curso de Magistério e } \\
\text { de habilitações na área } \\
\text { da gestão escolar. }\end{array}$ & $\begin{array}{l}\text { Para atuação no ensino de Primeiro e } \\
\text { Segundo Graus: } \\
\text { - Orientador educacional e supervisor } \\
\text { educacional; } \\
\text { - Administrador escolar; } \\
\text { - Inspetor de ensino. }\end{array}$ \\
\hline $\begin{array}{l}\text { Lei } \mathrm{n}^{\circ} \\
\text { 9.394/96 e } \\
\text { Diretrizes } \\
\text { de } 2006\end{array}$ & Licenciado & $\begin{array}{l}\text { Formação de docente } \\
\text { para atuar na formação } \\
\text { de professores do } \\
\text { Ensino Médio, na } \\
\text { Educação Infantil e } \\
\text { anos iniciais do Ensino } \\
\text { Fundamental, nas } \\
\text { atividades que } \\
\text { envolvem o apoio } \\
\text { escolar e na produção } \\
\text { de conhecimentos } \\
\text { científicos e } \\
\text { tecnológicos. }\end{array}$ & $\begin{array}{l}\text { Professor do curso de formação de docentes } \\
\text { de nível médio; } \\
\text { Professor da Educação Infantil; } \\
\text { Professor do Ensino Fundamental; } \\
\text { Atuar no apoio escolar, nas atividades de } \\
\text { planejamento, execução, coordenação, } \\
\text { acompanhamento e avaliação de tarefas } \\
\text { próprias do setor da Educação escolar e não } \\
\text { escolar; } \\
\text { Atuar na produção e difusão do } \\
\text { conhecimento científico-tecnológico do } \\
\text { campo educacional, em contextos escolares } \\
\text { e não escolares. }\end{array}$ \\
\hline
\end{tabular}

Fonte: Elaborado pelos autores.

\section{UM POUCO DA HISTÓRIA}

Ainda que, oficialmente, a formação de pedagogos tenha se iniciado a partir do Decreto $n^{\circ}$ 1.190/39 (BRASIL, 1939), já haviam sido tomadas iniciativas para a formação desse profissional, visando à sua atuação como professor na educação primária.

No final do século XVIII, os professores podiam ensinar apenas se tivessem determinada idade e uma licença concedida pelo Estado. Para isso, precisavam submeter-se a um exame no qual constavam pré-requisitos como conhecimentos relativos à área de atuação e ao comportamento moral julgado adequado pelo Estado. Com essa licença, tais pessoas passavam a ser consideradas professores e, ao mesmo tempo, acabava-se delimitando seu campo profissional, qual seja, o do ensino. 
Furet e Ozouf (1977) destacam que, nesse período, houve considerável expansão escolar. Isso ocorreu, dentre outros motivos, porque a instrução passou a ser compreendida como sinônimo de "superioridade social". A partir desse momento, as ações dos docentes passaram a ser valorizadas, bem como seu estatuto profissional, a ponto de eles serem considerados os "mestres-escolas" (termo utilizado para designar os professores de primeiras letras até, pelo menos, 1880).

Quanto à formação desse profissional, para realizá-la, não havia uma instituição de ensino específica. $\mathrm{O}$ recrutamento era realizado no próprio processo de aprendizagem dos alunos das primeiras letras. Em outros termos, se eles concluíam seu processo de escolarização, tinham um bom rendimento e comportamentos "adequados", podiam reivindicar o posto de auxiliares de professores (os chamados professores adjuntos) e, futuramente, poderiam até mesmo passar a serem "mestres-escolas".

Nóvoa (1992) considera que, embora a criação de instituições para a formação de professores fosse um projeto antigo, tornou-se possível somente no final do século XIX e início do século XX. Isso se deu por meio das escolas normais (magistério), instituições que visavam atender aos interesses do Estado e os dos próprios professores. Nesse momento, o velho "mestre-escola" passou a dar lugar a um novo personagem: o professor de instrução primária.

Segundo Nóvoa (1992), o perfil desse novo profissional pode ser assim resumido:

[...] não são burgueses, mas também não são povo; não devem ser intelectuais, mas têm de possuir um bom acervo de conhecimento; não são notáveis locais, mas têm uma influência importante nas comunidades; devem manter relações com todos os grupos sociais, mas sem privilegiar nenhum deles; não podem ter uma vida miserável, mas devem evitar toda ostentação; não exercem seu trabalho com independência, mas é útil que usufruam de alguma autonomia. (NÓVOA, 1992, p. 18).

Essas ambiguidades observadas no perfil do professor até o final do século XIX no Brasil refletem uma parte daquelas existentes também ao longo do século $\mathrm{XX}$, período em que legalmente foi oficializada a criação do curso de Pedagogia.

É importante registrarmos que, em 1934, o educador Fernando de Azevedo (18941974) inicia, em nível superior, a formação de professores no Instituto de Educação da Universidade de São Paulo - USP. No ano seguinte, é criada por Anísio Teixeira (1900-1971) a Escola de Educação da Universidade do Distrito Federal - UDF (EVANGELISTA, 2002).

Já a definição das atribuições do pedagogo só será realizada a partir do Decreto $\mathrm{n}^{\circ}$ 1.190/39 (BRASIL, 1939), do qual trataremos a seguir. 


\section{DECRETO No 1.190, DE 1939}

Em 1939, com a criação do Decreto no 1.190/39 (BRASIL, 1939), a Pedagogia passou a ser definida como o curso superior de formação de profissionais para atuarem na gestão escolar.

Dessa forma, era conferido ao estudante, depois de três anos de estudos formais, o título de bacharel. Para tal, conforme o Artigo 19 do Decreto, ele deveria cursar as disciplinas apresentadas na grade curricular do quadro 2, apresentado a seguir.

QUADRO 2 - Grade curricular do curso de Bacharel em Pedagogia.

\begin{tabular}{|l|l|}
\hline \multicolumn{1}{|c|}{ Séries } & \multicolumn{1}{c|}{ Disciplinas } \\
\hline \multirow{4}{*}{ Primeira série } & 1. Complementos de Matemática \\
& 2. História da Filosofia \\
& 3. Sociologia \\
& 4. Fundamentos Biológicos da Educação \\
& 5. Psicologia Educacional \\
\hline \multirow{5}{*}{ Segunda série } & 1. Estatística Educacional \\
& 2. História da Educação \\
& 3. Fundamentos Sociológicos da Educação \\
& 4. Psicologia Educacional \\
& 5. Administração Escolar \\
\hline Terceira Série & 1 História da Educação \\
& 2. Psicologia Educacional \\
& 3. Administração Escolar \\
& 4. Educação Comparada \\
& 5. Filosofia da Educação \\
\hline
\end{tabular}

Fonte: BRASIL, 1939.

Nesse sentido, os conteúdos ensinados visavam formar o bacharel em Pedagogia para desenvolver as seguintes atribuições: “[...] administração, planejamento de currículos, orientação a professores, inspeção escolar, avaliação do desempenho dos alunos e dos docentes, de pesquisa e desenvolvimento tecnológico da educação". (BRASIL, 2005, p. 2).

Esse tipo de formação era dirigido, principalmente, aos profissionais que tinham cursado o magistério e desejavam trabalhar na direção ou na coordenação das atividades em âmbito escolar. "Merece ser salientado que, nas primeiras propostas para este curso, a ele se atribuiu o "estudo da forma de se ensinar"”. (BRASIL, 2005, p. 2).

No texto introdutório do Parecer $n^{\circ} 252 / 69$ (BRASIL, 1969), no trecho que trata dos resultados da formação prevista no Decreto no 1.190/39 (BRASIL, 1939), porém, verifica-se que essa formação de "técnico em educação" chegou ao "quase descrédito". Ela era considerada genérica, não atingindo as expectativas de seus criadores. Afinal, os referidos estudantes do Bacharelado em Pedagogia não eram preparados para executar tais funções técnicas (nesses cursos, não havia habilitações). 
O aspecto generalista da formação, com atribuições pouco definidas, contribuiu ainda para o clientelismo no serviço público.

\begin{abstract}
Muito na linha de uma tradição clientelista do servidor público brasileiro, atenuouse gradativamente a exigência do curso à medida que os cargos, aqui e ali ocupados por profissionais realmente capazes, cresciam em número e ofereciam oportunidades para um emprego mais ou menos rendoso e de obrigação pouco definidas. Essa tendência atingiu tais proporções que, em dado momento, o título de "técnico de Educação" chegou quase ao descrédito. (BRASIL, 1969, p. 101)
\end{abstract}

Outra função estabelecida pelo Decreto $\mathrm{n}^{\circ}$ 1.190/39 (BRASIL, 1939) era a docência em cursos normais. Os alunos, caso desejassem, poderiam realizar mais um ano de estudos sobre conteúdos relacionados à didática e à prática de ensino. Para tanto, conforme o Artigo 20 do referido Decreto, deveriam, além de realizar estágio em prática de ensino, cursar as seguintes disciplinas: 1) Didática Geral; 2) Didática Especial; 3) Psicologia Educacional; 4) Administração Escolar; 5) Fundamentos Biológicos da Educação; e 6) Fundamentos Sociológicos da Educação (BRASIL, 1939).

O descrédito e o clientelismo observados na formação do bacharel também estavam presentes na licenciatura. Esses aspectos podem ser depreendidos das justificativas apresentadas no Decreto $\mathrm{n}^{\mathrm{o}}$ 8.558, de 1946 (as intituladas Leis Orgânicas de Ensino BRASIL, 1946) e do texto introdutório do Parecer $\mathrm{n}^{\circ}$ 252/69 (BRASIL, 1969), que apresentamos a seguir.

No setor privado, por ser menos dispendiosa, a admissão de professores não diplomados ainda continuou por muito tempo a constituir a regra mesmo nas grandes cidades. No setor público, o clientelismo também se fez sentir, embora com intensidade menor que a verificada no preenchimento dos cargos técnicos. (BRASIL, 1969, p. 102).

Os resultados dessa primeira normatização da formação de pedagogos não foram expressivos tanto para as funções técnicas em educação quanto para a docência. Consequentemente acabou prevalecendo uma atuação profissional intuitiva (calcada no senso comum), constituída por saberes da experiência construída a partir do cotidiano escolar.

Nos anos 1950, iniciou-se um período marcado pela disseminação de teorias pedagógicas provindas dos EUA, expressas como "tecnicismo educacional" (LIBÂNEO, 2006). Tal tendência começou a influenciar a formação de pedagogos e, por conseguinte, a demarcar as suas atribuições, isto é, esses profissionais passaram a ser preparados, principalmente a partir de 1969, para realizar determinadas atividades, quais sejam: inspeção escolar, supervisão escolar, orientação educacional e direção escolar (atendendo a determinações estatais).

É nesse contexto que, em 1961, foi aprovada a primeira Lei de Diretrizes e Bases da Educação Nacional (BRASIL, 1961). 


\section{A LEI No 4.024, DE 1961, E O PARECER N 251, DE 1962}

A Lei $\mathrm{n}^{\circ}$ 4.024/61 (BRASIL, 1961), em conformidade com o Decreto $\mathrm{n}^{\circ}$ 8.530/46 (BRASIL, 1946), possibilitou a formação do pedagogo para atuar como docente da educação primária em institutos de educação.

Abriu também a possibilidade de oferta de cursos de aperfeiçoamento em administração para os profissionais que possuíssem formação em escolas normais (equivalente, nos dias atuais, à formação de docentes no Ensino Médio), conforme o Artigo 55 da referida Lei (BRASIL, 1961).

Essa Lei defende que a formação para a docência no nível médio deve ser feita em cursos superiores. Com isso, abre-se espaço para que os institutos de educação a ofertem, desde que respeitem as normas estabelecidas para os cursos pedagógicos das faculdades.

Nesse sentido, a Lei 4.024/61 (BRASIL, 1961) retoma o Artigo 59 do Decreto 1.190/39 (BRASIL, 1939): a docência no Ensino Médio deve ser feita em institutos de educação. Dessa Lei (BRASIL, 1961) decorreu o Parecer nº 251/62 (BRASIL, 1962). Assim como em outros aspectos, tomando por base o Decreto $\mathrm{n}^{\circ}$ 1.190/39 (BRASIL, 1939), este estabeleceu o currículo mínimo para o curso de Pedagogia, evidentemente com algumas modificações curriculares, como por exemplo: matérias pedagógicas das disciplinas do curso de Didática foram inseridas no curso do "técnico pedagógico". Além disso, manteve a formação para o Bacharelado e a Licenciatura, considerando o modelo de 1939.

Nota-se que, legalmente, durante o período de 1939 a 1961, a formação do pedagogo sofreu poucas alterações curriculares. Assim, as atribuições profissionais permaneceram basicamente genéricas, alimentando, no caso do serviço público, o clientelismo.

\section{LEI No 5.540, DE 1968, E PARECER N² 252, DE 1969}

Em 1968, entrou em vigor a Lei n 5.540 (BRASIL, 1968), que estabeleceu como prerrogativa dos cursos de Pedagogia a formação de professores para atuar no ensino de Segundo Grau (o atual Ensino Médio) e no âmbito da gestão escolar, como já havia sido feito em legislações anteriores (Decreto $n^{\circ}$ 1190/39, BRASIL/39; Parecer $n^{\circ}$ 251/1962, BRASIL/62).

A diferença foi que se criaram habilitações específicas para formar gestores escolares (Supervisão, Orientação Educacional e Administração). Além disso, no Artigo 30 da referida Lei, enfatizou-se que o profissional formado em Pedagogia deveria inspecionar o trabalho pedagógico desenvolvido pelos docentes (BRASIL, 1968). Por conseguinte, visou-se oferecer formação técnica aos pedagogos dedicados à gestão e, ao mesmo tempo, introduzir 
representantes da sociedade política nas escolas cuja função básica era a de vigiar e delatar os profissionais que, porventura, estivessem realizando alguma atividade julgada subversiva.

Consequentemente enfatizou-se ainda mais o espírito conservador da atuação do pedagogo, visto que se objetivava atender às demandas da economia vigente e do Estado por meio da veiculação e manutenção da ideologia governamental que, por sua vez, era a da classe social dominante.

No ano seguinte (1969), como resultado da referida Lei (BRASIL, 1968), foi regulamentado pelo Conselho Federal de Educação o Parecer no 252/69 (BRASIL, 1969) e a Resolução $\mathrm{n}^{\mathrm{o}} 2$ do mesmo Conselho. Tais normas confirmaram o estabelecido pela Lei $\mathrm{n}^{\circ}$ 5.540 (BRASIL, 1968), isto é, a formação de especialistas destinados ao trabalho técnico (inspeção, planejamento, supervisão, orientação, entre outros) e a unidade entre bacharelado e licenciatura (BRASIL, 1968).

Dessa forma, o curso passou a ter uma parte comum, constituída de matérias básicas, e outra de cunho mais profissionalizante, chamada de "parte diversificada". Além disso, o Artigo $3^{\circ}$ da referida Lei $\mathrm{n}^{\circ} 5.540$ (BRASIL, 1968) extinguiu o título de bacharel para o pedagogo e fixou o título de licenciado para o concluinte do curso de Pedagogia com habilitações para desempenhar as variadas atribuições demandadas pela escola (a Docência no Curso Normal, a Supervisão, a Orientação Educacional, a Administração, entre outras) (BRASIL 1968).

Sublinhamos que o pedagogo podia exercer o ofício de professor do Ensino Médio, como previsto já em 1939, e, igualmente, a docência nas séries iniciais do atual Ensino Fundamental. Todavia, alinhado ao que estabelecia o Parecer $n^{\circ}$ 252/69 (BRASIL, 1969), a atuação nas séries iniciais não determinava mais o eixo curricular da formação do pedagogo, mas era compreendida como decorrência da formação ofertada (BRASIL, 2005). Nas entrelinhas da legislação, estava o pressuposto de que quem podia lecionar no Segundo Grau (Curso Normal) também poderia ser professor das séries iniciais do Primeiro Grau (atual Ensino Fundamental) (BRASIL, 1969).

Mesmo com o estabelecido pelo Parecer 252/69 (BRASIL, 1969), a formação do docente para o ensino de Primeiro Grau ainda era predominantemente desempenhada por professores formados em cursos normais secundários. A partir dos anos 1980, a docência para o ensino do primeiro grau transformou-se em mais uma habilitação: as chamadas "séries iniciais". Tal criação ocorreu por causa do declínio dos cursos de formação de professores no Segundo Grau, o chamado "Magistério", que, em virtude da ausência de políticas públicas e de investimento financeiro, aliada à falta de valorização desses profissionais, provocou sua baixa procura por parte da população, o que, entre outros aspectos, contribuiu para a quase cessação da oferta desses cursos. 
Permaneceram, entretanto, os problemas atinentes às atribuições pedagógicas. Estas sempre estiveram, de um lado, atreladas às demandas políticas de governos e, de outro, distantes de uma problematização que considerasse as reais necessidades escolares.

Por exemplo: de acordo com Silva (1999), a reforma proposta para o curso de Pedagogia não rompeu com a fragmentação entre a docência e o bacharelado e entre as demandas do cotidiano escolar e a idealização observada nos cursos de formação inaugurada na década de 1930.

Tal característica contribuiu substancialmente para a existência e a cristalização das dificuldades que os pedagogos atualmente enfrentam no tocante à sua atuação no campo da gestão escolar. Retomando Saviani (2007a), podemos afirmar que as atribuições do pedagogo foram moldadas com base em um perfil de indução conservadora e em uma "concepção produtivista de educação". Em outras palavras, o citado cientista afirma que desde o Império as demandas sociais têm sido subordinadas aos recursos disponibilizados ao campo educacional (e não o contrário).

Nesse sentido, as ações que compuseram as atribuições para a organização do trabalho pedagógico escolar no campo da gestão foram estabelecidas tendo como principal referência os interesses políticos e econômicos governamentais. Com isso, confirmou-se o distanciamento entre a formação e as demandas da educação e das práticas educativas, conforme mostra o trecho do Parecer $\mathrm{n}^{\circ}$ 05/2005 a seguir.

Essa situação levou os cursos de Pedagogia a enfrentarem, nem sempre com sucesso, a problemática de equilíbrio entre formação e exercício profissional, bem como as desafiantes críticas de que os estudos em Pedagogia dicotomizavam a teoria e prática. (BRASIL, 2005, p. 4).

Sabemos que a organização do trabalho escolar inspirou-se nos modelos de administração taylorista/fayolista. Essas concepções desencadearam uma moldura ideológica ainda presente na atuação do pedagogo que fragmenta as ações escolares em administrativas e pedagógicas. Contudo, também sabemos que o que caracteriza as ações é a sua finalidade. Nesse sentido, as ações escolares visam ao ensinar e ao aprender; portanto, todas as atribuições escolares do pedagogo deveriam ser compreendidas como pedagógicas.

Tomaram forma, ainda nos anos 1980, os movimentos formados por educadores que resistiram ao poder instituído e questionaram as reformas estabelecidas durante a ditadura militar (SAVIANI, 2007b). "Inseridos nestas manifestações, também, estavam os questionamentos sobre o caráter científico da Pedagogia, e as suas aproximações com as ciências da educação". (PIMENTA, 2006, p. 10).

Saviani (2007b) afirma que a Anped (Associação Nacional de Pesquisa e PósGraduação em Educação), a Andes (Associação Nacional de Docentes do Ensino Superior),

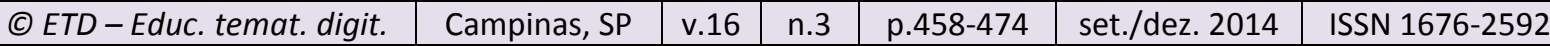


o Cedes (Centro de Estudos Educação \& Sociedade), a CNTE (Confederação Nacional dos Trabalhadores da Educação), o Forumdir (Fórum Nacional de Diretores de Faculdade, Centros de Educação e Equivalentes) e a Anfope (Associação Nacional pela Formação de Profissionais de Educação) realizaram diversas reuniões, fóruns e debates sobre o anteprojeto da Lei de Diretrizes e Bases da Educação Nacional (BRASIL, 1996) por ocasião da abertura democrática no Brasil. Esses eventos tinham como um dos assuntos principais a formação dos pedagogos e suas atribuições, considerando-se a nova organização do sistema nacional de Educação, assunto que trataremos a seguir.

\section{A LEI No 9.394, DE 1996, E AS DIRETRIZES CURRICULARES NACIONAIS PARA O CURSO DE PEDAGOGIA, DE 2006}

A promulgação da Lei de Diretrizes e Bases da Educação Nacional - LDB (BRASIL, 1996) intensificou os debates sobre a identidade do curso de Pedagogia e, consequentemente, sobre as atribuições do pedagogo. Por causa disso, foi estabelecida a necessidade de regulamentação da formação de pedagogos em vários aspectos, diante das contradições que a LDB/96 apresentou, entre elas, a retirada da formação de docentes para os anos iniciais do Ensino Fundamental do curso de Pedagogia, transferindo-a para os institutos superiores de educação:

Art. 62. A formação de docentes para atuar na educação básica far-se-á em nível superior, em curso de licenciatura, de graduação plena, em universidades e institutos superiores de educação, admitida, como formação mínima para o exercício do magistério na educação infantil e nas quatro primeiras séries do ensino fundamental, a oferecida em nível médio, na modalidade Normal. (BRASIL, 1996).

O curso de Pedagogia, que até então formava profissionais para lecionar nas séries iniciais e, recentemente, tinha começado a atender a uma nova demanda (a formação para a docência na Educação Infantil), além da formação para a atuação no campo da gestão, sem uma formalização legal dessas habilitações, foi alvo de intensos debates e questionamentos sobre as reais atribuições de seu egresso.

Essas reflexões influenciaram a construção das Diretrizes Curriculares para o Curso de Pedagogia - DCNCP, regulamentada em 2005 mediante o Parecer $\mathrm{n}^{\circ} 05$ (BRASIL, 2005) e, em 2006, pela Resolução no 1 (BRASIL, 2006), de 15 de março, que apresentou a extinção de todas as habilitações até então ofertadas e trouxe de volta a formação de professores para atuar na Educação Infantil e nos anos iniciais do Ensino Fundamental, posicionamento contrário ao previsto pela LDB/96 (BRASIL, 1996), que extinguiu essa oferta nos institutos superiores, como mostra o Artigo $2^{\circ}$ da referida Resolução:

Art. $2^{\circ}$ As Diretrizes Curriculares para o curso de Pedagogia aplicam-se à formação inicial para o exercício da docência na Educação Infantil e nos anos iniciais do Ensino Fundamental, nos cursos de Ensino Médio, na modalidade Normal, e em cursos de Educação Profissional na área de serviços e apoio escolar, bem como em 
outras áreas nas quais sejam previstos conhecimentos pedagógicos. (BRASIL, 2006).

Outro conflito com a LDB/96 (BRASIL, 1996) é apresentado pelo Artigo 64 da Resolução $\mathrm{n}^{\circ} 1$ (BRASIL, 2006). Este prevê a formação para atuação no campo da gestão em cursos de graduação ou de pós-graduação. As Diretrizes de 2006 (BRASIL, 2006) enfatizam que essa formação para o "apoio escolar" deve ocorrer na graduação em Pedagogia, acentuando a compreensão de que a atuação no campo da gestão faz parte das atribuições do pedagogo. Dessa forma, as referidas Diretrizes estabelecem que só os profissionais formados em Pedagogia podem atuar nas atividades que envolvem a gestão escolar.

Ainda sobre as Diretrizes de 2006, elas estabelecem o conceito ampliado de docência, como já dissemos. Basicamente, os educadores pertencentes a entidades de classe, sendo a principal delas a Anfope, defendiam a docência como identidade profissional de todo educador; daí o entendimento da citada entidade de que, se o pedagogo é educador, sua identidade principal firma-se na docência (AGUIAR; SCHEIBE, 1999). Isso não significa que a identidade profissional, como a do pedagogo, se reduz a um eixo de formação (por exemplo, a docência).

Aguiar et al. (2006, p. 9-10) consideram que as DCNP apontam para "uma nova concepção da educação, da escola, da Pedagogia, da docência, da licenciatura", ampliando o sentido da docência. Esta deixa de se restringir ao ato de ministrar aulas, articulando-se a outras atribuições do trabalho pedagógico, que também pode ser desenvolvido em espaços não escolares.

Diante dessa nova visão, o pedagogo passa a ter a prerrogativa de desempenhar as seguintes atribuições: a docência na Educação Infantil, nos anos iniciais do Ensino Fundamental e na formação de docentes no Ensino Médio. Além disso, ele pode desempenhar ações de apoio escolar: planejamento, execução, coordenação, acompanhamento e avaliação de tarefas próprias da educação e pesquisa (produção e difusão do conhecimento científico) (BRASIL, 2006).

Todavia, questionamos: as Diretrizes Curriculares e as atribuições do pedagogo delas decorrentes não estariam atendendo também à lógica de mercado, no contexto neoliberal, isto é, à formação de um profissional "multitarefeiro"? Não estamos assistindo, sob uma nova roupagem, às velhas funções do pedagogo, pois ele continua a reproduzir a lógica do capitalismo, assim como ocorreu nos anos 1960? Mais especificamente, como alerta Saviani (2007a), não se está reafirmando a "pedagogia de resultados", com baixo investimento e pouca especificidade? Não estaríamos reafirmando a função de tecnocrata ao pedagogo - que foi estabelecida por ocasião da ditadura militar?

Se olharmos à frente, no século XXI, gradativamente, com as reformas políticas de favorecimento do "crescimento econômico", impõem-se com uma nova lógica, teorias que

\begin{tabular}{l|l|l|l|l|l|l} 
(C) ETD - Educ. temat. digit. & Campinas, SP & v.16 & n.3 & p.458-474 & set./dez. 2014 & ISSN 1676-2592
\end{tabular}


passam a influenciar os processos produtivos no Brasil, principalmente o toyotismo, como aponta Dowbor $(1999$, p. 8):

\begin{abstract}
Os paradigmas de gestão que herdamos - basta folhear qualquer revista de administração — têm todos sólidas raízes industriais. Só se fala em taylorismo, fordismo, toyotismo, just-in-time e assim por diante. Como é que se faz um plano just-in-time? Ou educação em cadeia de montagem? Um Cad-Cam cultural?.
\end{abstract}

Em decorrência, a formação de pedagogos e suas atribuições não ficam isentas dessas transformações. Por conseguinte, o discurso político passa a requerer um profissional "polivalente". Contudo, na verdade, acaba-se "fabricando" um profissional que faz parte de uma engrenagem social. Por causa disso, ele executa dada tarefa, perdendo, consequentemente, a visão do todo. Nesse sentido, mantém-se tal profissional alienado, reafirmando o taylorismo e o toyotismo.

\title{
9 CONSIDERAÇÕES FINAIS
}

Atuar na educação implica promover processos educativos que objetivam a humanização, e o pedagogo é, sem dúvida, um dos responsáveis por esses processos.

Como apontamos inicialmente, as atribuições desse profissional foram delegadas apenas àqueles que desempenhavam a docência em sentido restrito (planejar, avaliar e ensinar). A partir das Diretrizes Curriculares Nacionais (BRASIL, 2006), o sentido de docência foi ampliado, integrando as funções de gestor e de pesquisador.

A docência ampliada como base comum da formação do pedagogo, presente nas citadas diretrizes curriculares, foi decorrência de constantes reivindicações feitas pela Anfope. Nesse sentido, a docência além de ser um elemento unificador da profissão, pretendia superar a fragmentação na formação estabelecida.

Esse posicionamento foi criticado por educadores como Libâneo (2006) e Pimenta (2006). Para estes, o pedagogo deve ser um cientista da educação, ou seja, um educador não docente.

Depreendemos, assim, que até os dias atuais há uma polêmica em relação às atribuições do pedagogo. Para alguns estudiosos, a ênfase deve ser dada à docência no sentido ampliado; para outros, à pesquisa.

Dessa forma, chamamos a atenção para o fato de que as Diretrizes Curriculares Nacionais podem não representar um avanço, mas ao contrário, reforçar a ideia de que o pedagogo deve ser um "faz-tudo", reafirmando a herança histórica da época da ditadura militar que o definiu como um tecnocrata. 
Em outras palavras, nossa análise apontou que as atuais Diretrizes Curriculares Nacionais ampliaram as atribuições do pedagogo em relação aos demais marcos legais. Todavia, essa ampliação pode transformá-lo em um profissional polivalente, favorecedor de uma realidade ideologicamente vazia (falseadora do real) e sem sentido para os cursos de Pedagogia.

A ilusão de "poder" dada ao pedagogo (inspetoria, direção e gestão) lhe é retirada quando delegam a ele tantas outras funções. Na prática, o acúmulo de tarefas e a diversidade de papéis desempenhados geraram uma não identificação do próprio profissional com sua profissão.

Dessa forma, não foi superado o distanciamento histórico entre o cotidiano escolar e a formação prevista para o pedagogo; aspecto, a nosso ver, imprescindível à construção de processos escolares humanizadores.

\section{REFERÊNCIAS}

AGUIAR, Márcia Ângela da Silva et. al. Diretrizes Curriculares do Curso de Pedagogia no Brasil: disputas de projetos no campo da formação do profissional da educação. Educação e Sociedade, Campinas, SP, v.27, n. 96, p. 819-842, out. 2006.

AGUIAR, Márcia; SCHEIBE, Leda. Formação de profissionais da educação no Brasil: o curso de Pedagogia em questão. Educação e Sociedade, Campinas, SP, v.20, n. 68, p. 220 238, dez. 1999.

BRASIL. Congresso Nacional. Lei n. 4.024, de 20 de dezembro de 1961. Fixa as diretrizes e bases da educação nacional. Documenta, Brasília, DF, n.1, 1962.

BRASIL. Conselho Federal de Educação. Parecer n. 252/1969. Estudos pedagógicos superiores. Mínimos de conteúdos e duração para o curso de graduação em Pedagogia. Relator: Valnir Chagas. Documenta, DF, Brasília, n.100, p. 101-179, 1969.

BRASIL. Decreto-Lei n. 1.190, de 4 de abril de 1939. Organização da Faculdade Nacional de Filosofia. Diário Oficial da União, Brasília, DF, Diário oficial da União, 6 abr. 1939. Seção 1, p. 7.929 .

BRASIL. Decreto-Lei n. 8.558, de 4 de janeiro de 1946. Cria cargos isolados de provimento efetivo, no Quadro Permanente do Ministério da Educação e Saúde e dá outras providências. 1946. (Mimeog.).

BRASIL. Ministério da Educação. Conselho Nacional de Educação. Parecer 05/2005. Estabelece as diretrizes curriculares nacionais para o curso de Pedagogia. Ministério da Educação, 2005. Disponível em: 〈http://portal.mec.gov.br/cne/arquivos/pdf/pcp05_05.pdf〉. Acesso em: 3 nov. 2014. 
BRASIL. Ministério da Educação. Lei 5.540, de 28 de novembro de 1968. Fixa normas de organização e funcionamento do ensino superior e sua articulação com a escola média e dá outras providências. Ministério da Educação, 1968. Disponível em:

<http://www.planalto.gov.br/ccivil_03/leis/15540.htm>. Acesso em: 3 nov. 2014.

BRASIL. Ministério da Educação. Lei 9.394, de 20 de dezembro de 1996. Estabelece as diretrizes e bases da educação nacional. Ministério da Educação, 1996. Disponível em: <http://www.planalto.gov.br/ccivil_03/leis/19394.htm>. Acesso em: 3 nov. 2014.

BRASIL. Resolução CNE/CP 1/2006. Diretrizes Curriculares Nacionais para o Curso de Pedagogia. Diário Oficial da União, Brasília, DF, n. 92, 2006. Seção 1, p. 11-12. Disponível em: <http://portal.mec.gov.br/cne/arquivos/pdf/rcp01_06.pdf>. Acesso em: 3 nov. 2014.

BREZEINSKI, Iria. Pedagogia, pedagogos e formação de professores: busca e movimento. Campinas, SP: Papirus, 1996.

CAMPOS, Roselane. A definição das diretrizes para o curso de Pedagogia. In: ENCONTRO NACIONAL DA ANFOPE, 12., 2004, Brasília, DF. Anais... Brasília, DF: ANFOPE, 2004. Disponível em: <http:// www. anped.org.br>. Acesso em: 18 set. 2014.

DOWBOR, Ladislau. Tendências da gestão social. Saúde e Sociedade, São Paulo, SP, v. 8, n. 1, p. 3-16, fev. 1999. Disponível em: <http://www.scielo.br/pdf/sausoc/v8n1/02.pdf〉. Acesso em: 10 nov. 2014.

EVANGELISTA, Olinda. A formação universitária do professor: o Instituto de Educação da Universidade de São Paulo (1934-1938). Florianópolis: NUP/CED/UFSC/Cidade Futura, 2002.

FURET, François; OZOUF, Jacques. Lire et écrire. Paris: Minuit, 1977.

GIL, Antonio Carlos. Como elaborar projetos de pesquisa. São Paulo: Atlas, 2002.

KÜENZER, Acacia Zenaide; RODRIGUES, Marli de Fátima. As diretrizes curriculares para o curso de Pedagogia: uma expressão da epistemologia da prática. In: SILVA, A. M. et al. (Org.). Novas subjetividades, currículo e questões pedagógicas na perspectiva da inclusão social. Recife: Bagaço, 2006. p. 185-202. Disponível em: 〈http://ced.ufsc.br〉. Acesso em: 10 nov. 2011.

LIBÂNEO, José Carlos. Formação dos profissionais da educação: visão crítica e perspectivas de mudança. In: PIMENTA, S. G. Pedagogia e pedagogos: caminhos e perspectivas. São Paulo: Cortez, 2006. p. 11-57.

NÓVOA, Antonio. Os professores e a sua formação. Lisboa: Publicações Dom Quixote, 1992.

PIMENTA, Selma Garrido. Pedagogia e pedagogos: caminhos e perspectivas. São Paulo: Cortez, 2006.

SAVIANI, Demerval. Da nova LDB ao Fundeb: por uma outra política educacional. Campinas, SP: Autores Associados, 2007a.

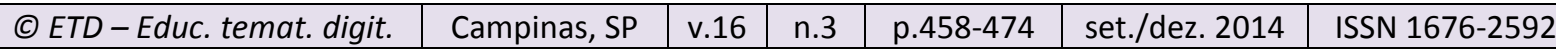


SAVIANI, Demerval. Pedagogia: o espaço da educação na universidade. Cadernos de Pesquisa, São Paulo, SP, v. 37, n. 130, p. 99-134, 2007b. Disponível em:

<http://dx.doi.org/10.1590/S0100-15742007000100006>. Acesso em: 3 nov. 2014.

SCHEIBE, Leda; DURLI, Zenilde. Curso de Pedagogia no Brasil: olhando o passado, compreendendo o presente. Educação em Foco, Belo Horizonte, v. 14, n. 17, p. 79-109, jul. 2011. Disponível em: <http://www.uemg.br/openjournal/index.php/educacaoemfoco/article /view/104>. Acesso em: 25 out. 2014.

SILVA, Carmem Silvia Bissolli da. Curso de pedagogia no Brasil: história e identidade. Campinas, SP: Autores Associados, 1999.

\section{Como citar este documento:}

LOPES, Rosana Sousa Pereira; BIANCHINI, Luciane Guimarães Batistella; SILVA, Nelson Pedro. Marcos legais para os Cursos de Graduação em Pedagogia no Brasil: análise das atribuições do pedagogo. ETD - Educação Temática Digital, Campinas, SP, v. 16, n. 3, p.458-474, set./dez. 2014. ISSN 1676-2592. Disponível em: <http://www.fe.unicamp.br/revistas/ged/etd/article/view/6874>. Acesso em: 23 dez. 2014. 